\title{
Cutaneous squamous cell carcinoma arising from the hair follicle
}

\section{Vladimír Bartoš}

\author{
Department of Pathology, Faculty Hospital in Žilina, Slovakia
}

Corresponding author: Vladimír Bartoš, MD., PhD, e-mail: vladim.bartos@gmail.com

Sir,

Squamous cell carcinoma (SCC) is the second most common malignant neoplasia of the skin. It includes many subtypes with varying histomorphology and clinical behaviour. General view assumes that a vast majority of the cases arise from the surface epidermis. However, a follicular (infundibular) cutaneous SCC has also been described [1-3]. It is defined as a SCC arising from the wall of the hair follicle. Although the hair follicle structures contain a stratified squamous epithelium similar to that in the surface epidermis, in fact, it is considered to be an uncommon origin of cutaneous SCC. Here, I briefly report a case of this histopathology entity.

A 68-year old woman manifested with a slightly protuberated skin tumor on the dorsum of the nose. She claimed the lesion had been present for half year. On gross examination, it was gray-brownish and well-defined with $7 \mathrm{~mm}$ in diameter. A presumptive clinical diagnosis was basal cell carcinoma. A total surgical extirpation was done. Histology revealed a well differentiated keratinizing SCC deriving from a preexisting hair follicle structure without a demonstratable epidermal point of origin (Fig. 1). A contiguous transition of normal squamous epithelium of the hair follicle and malignant tumor tissue was visible (Fig. 2). An overlying epidermis showed no keratinocyte atypia and it did not have a direct contact with cancer. This was well demonstrated by immunohistochemistry using a high molecular weight cytokeratins antibody (clone 34betaE12) (Fig. 3). At the periphery, the tumor exhibited an infiltrative growth pattern accompanied by massive chronic inflammatory cellulisation in the stroma. The Ki-67 proliferation index (clone MIB-1) of the neoplastic cells exceeded $50 \%$, while the overlying epidermis demonstrated a nuclear Ki-67 reactivity only in the basal cell layer. No signs of trichilemmal or hair matrix differentiation were found.

Until now, a few series of follicular (infundibular) SCC of the skin have been reported [1-3]. The largest set of the cases has been published by Shedrik et al. [1]. In a database of 5212 primary cutaneous SCCs diagnosed over 5-year period, they identified 61 cases (1.2\%) of follicular SCC from 60 individuals. The mean age of the patients was 74 years. Histologically, the lesions were divided into the following two subtypes. If the tumor exclusively arose from the hair follicle, it was called "pure“ follicular SCC (49 cases). If an interfollicular epidermal origin was also demonstrated (only SCCs with $<50 \%$ of the origin from interfollicular epidermis were included), the lesions were considered „hybrid“ SCC (12 cases).

Another research addressing follicular SCCs has been conducted by Diaz-Cascajo et al. [2]. Among more than 7000 cases of cutaneous SCC, they found 16 cases of SCC developing in hair follicles $(0.2 \%)$. A majority arose on sun-damaged skin, typically on the face of elderly persons. Microscopically, the tumors developed in the upper parts of hair follicles, replacing the follicular epithelium with full-thickness atypical keratinocytes and invading into the surrounding dermis. The neoplastic cells possessed features of squamous differentiation, such as abundant eosinophilic cytoplasm, hyperchromatic nuclei with prominent nucleoli, occasional dyskeratotic cells, and central keratinization. In most cases, there was an abrupt transition of malignant epithelium with the adjacent bland-appearing epidermis. All tumors were immunohistochemically negative for a broad spectrum of antibodies against human papillomaviruses, indicating no viral (HPV) etiology. They concluded,

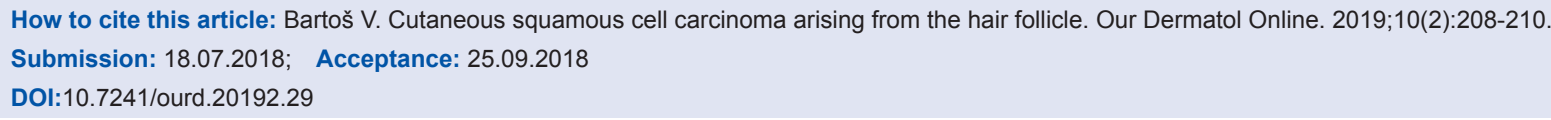




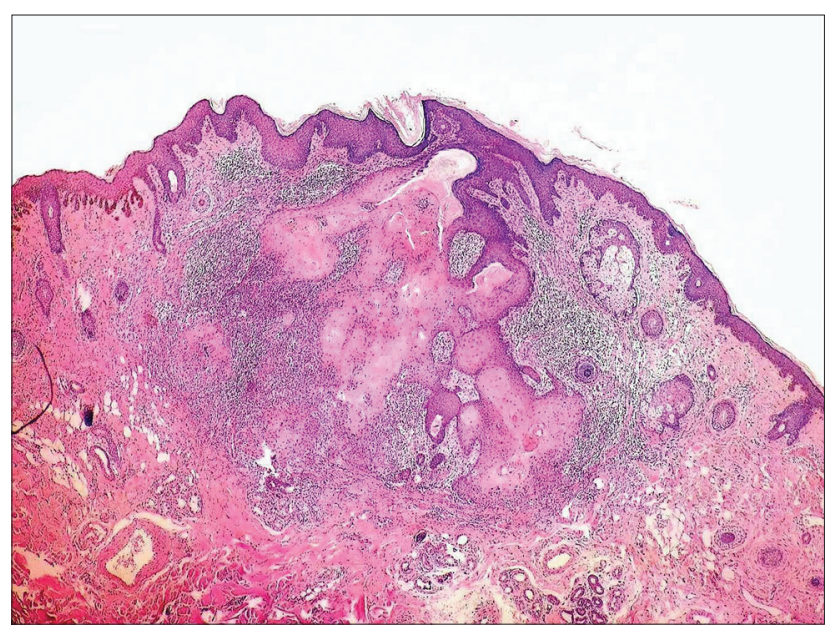

Figure 1: A conventional keratinizing SCC deriving from a pre-existing hair follicle structure. At the left side, an invasive front of tumor is visible. (hematoxylin \& eosin, magnification 40x)

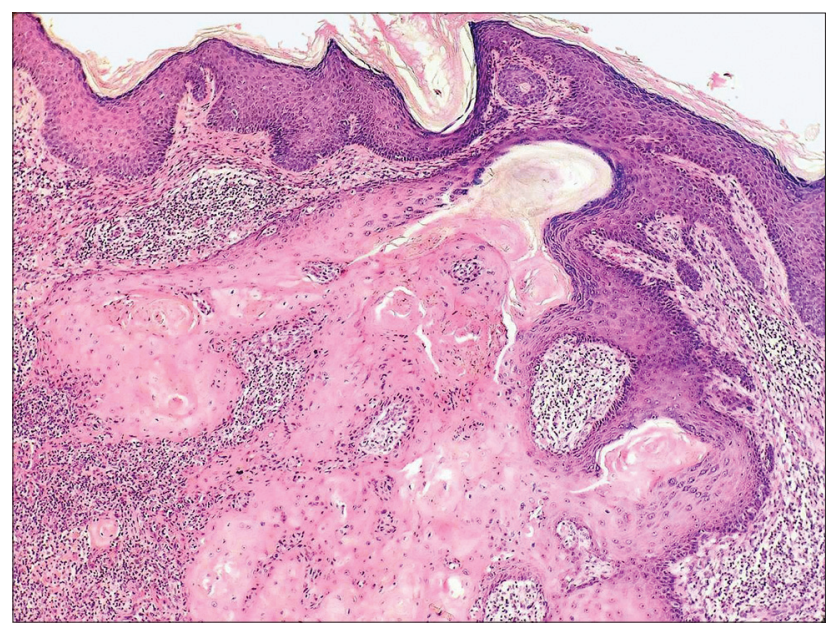

Figure 2: A contiguous transition of normal squamous epithelium of the hair follicle remnant (right) and tumor tissue (left). (hematoxylin \& eosin, magnification 100x)

SCC of the hair follicle represents a poorly recognized but distinctive subset of SCC of the skin that should be considered in the differential diagnosis of other cutaneous epithelial neoplasms.

In another study, Misago et al. [3] examined 6 follicular (infundibular) SCCs, which were subclassified into: a) the common ( 2 cases) and, b) the crater forms (4 cases). In accordance with the previous authors, all lesions were located on the head. They had a clinical history of slow growth. Except for one case, which showed regional lymph node metastasis 3 years after the excision, no recurrence or metastasis was seen during the follow-up period.

Based on my own experience, I consider a follicular SCC of the skin to be somewhat controversial issue. Although literally reported occurrence is very low

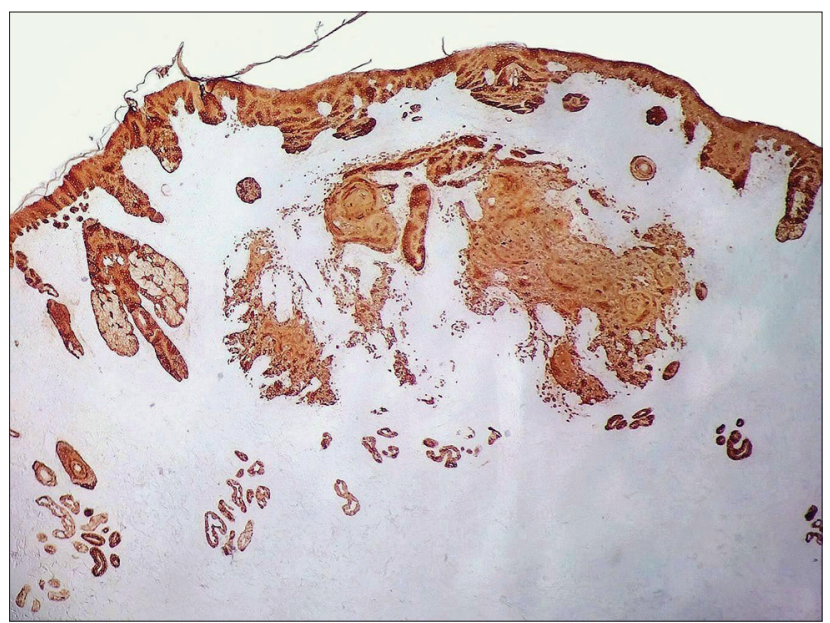

Figure 3: Strong immunoreactivity for high molecular weight cytokeratins in SCC tissue and in the surface epidermis. No contact of tumor with a surface epidermis is evident. (magnification 40x)

(about $1 \%$ of all cutaneous SCCs), some authors $[1,4]$ have suggested that an incidence is much higher and this SCC variant is under-recognized. In my opinion, it is very difficult to estimate a true incidence of follicular SCC for several reasons. I feel a crucial problem in that features of follicular differentiation or remnants of the hair follicle structures may dissapear as tumor enlarges and spreads into the surrounding tissue. These histomorphologic signs are usually well identifiable in early stage of tumor growth, such as in the present case, but they may vanish over time in more advanced lesions. Further, as tumor tissue of many invasive cutaneous SCCs contain „entrapped“ hair follicles, of which the squamous epithelium underwent malignant changes, it is impossible to define, whether they represent a primary source of malignancy, or only a secondary involvement by tumor. By definition, a follicular SCC represents a truly follicular tumor demonstrating infundibular differentiation and not merely the replacement of the hair follicles by SCC. Another question arises, whether the infundibulum has a frank follicular origin that possesses distinct biological properties, or it is only an extension of the epidermis. I personally agree with a comment of Klingman and Chen [5], who did not see a practical reason to use the term follicular or infundibular cutaneous SCC as a distinct histopathologic entity. From a clinical point of view, a prognosis probably does not depend on whether cutaneous SCC arise from the surface epidermis or from the wall of the hair follicle.

\section{Consent}

The examination of the patient was conducted according to the Declaration of Helsinki principles. 
www.odermatol.com

\section{REFERENCES}

1. Shendrik I, Crowson AN, Magro CM. Follicular cutaneous squamous cell carcinoma: an under-recognized neoplasm arising from hair appendage structures. Br J Dermatol. 2013;169:384-88.

2. Diaz-Cascajo C, Borghi S, Weyers W, Bastida-Inarrea J. Follicular squamous cell carcinoma of the skin: a poorly recognized neoplasm arising from the wall of hair follicles. J Cutan Pathol. 2004;31:19-25.

3. Misago N, Inoue T, Toda S, Narisawa Y. Infundibular (follicular) and infundibulocystic squamous cell carcinoma: a clinicopathological and immunohistochemical study. Am J Dermatopathol. 2011;33:687-94.
4. Carr R, Taibjee S, Turnbull N, Attili S. Follicular squamous cell carcinoma is an under-recognised common skin tumour. Diagn Histopathol. 2014;20:289-96.

5. Klingman DE, Chen S. Infundibular squamous cell carcinoma: A new entity? Am J Dermatopathol. 2012;34:676-7.

Copyright by Vladimír Bartoš. This is an open-access article distributed under the terms of the Creative Commons Attribution License, which permits unrestricted use, distribution, and reproduction in any medium, provided the original author and source are credited.

Source of Support: Nil, Conflict of Interest: None declared. 